Polymer Journal, Vol. 10, No. 3, pp 287-292 (1978)

\title{
Synthesis and Characterization of Poly( $N$-cyanoethylglycine)
}

\author{
Yukio Imanishi, Toshio Tsuchida, ${ }^{*}$ and Toshinobu Higashimura \\ Department of Polymer Chemistry, Kyoto University, \\ Yoshida, Sakyo-ku, Kyoto 606, Japan.
}

(Received October 5, 1977)

\begin{abstract}
N$-Cyanoethylglycine was synthesized from glycine and acrylonitrile, and converted into its $N$-carboxyanhydride (NCA) by Leuch's method. The NCA was polymerized in a $\mathrm{HCONMe}_{2}$ solution using an amine as the initiator to give, for the first time, a white, powderic, amorphous polymer having $\overline{\boldsymbol{P}}_{n}=15-16$. The rate of polymerization was much smaller than that of $N$-n-butylglycine NCA under the same conditions, and the low basicity of the amino group at the growing end, which is a result of an electron-withdrawing effect of cyanoethyl group, was found to be responsible for the slow polymerization. Poly $(N$-cyanoethylglycine $)$ is soluble in aprotic solvents such as $\mathrm{HCONMe}_{2}, \mathrm{Me}_{2} \mathrm{SO}$, and $\mathrm{Me}_{2} \mathrm{CO}$, and its main-chain peptide bonds comprise ca. 70\% of cis form and ca. 30\% of trans form in $\mathrm{Me}_{2} \mathrm{SO}$. Poly(N-cyanoethylglycine) is therefore flexible and compact in organic solvents. A part of the side chains of $\operatorname{poly}(N$ cyanoethylglycine) was reduced into 3-aminopropyl groups by the hydrogenation.
\end{abstract}

KEY WORDS $N$-Cyanoethylglycine NCA / Polymerizability / Poly( $N$-cyanoethylglycine) / Characterization / Hydrogenation / Poly $(N$-3-aminopropylglycine $) /$

Polymers carrying pendant reactive groups such as the cyanoethyl group are useful as functional materials. ${ }^{1}$ Poly( $\alpha$-amino acid) carrying pendant cyanoethyl groups, however, has not been reported. Among many possible reactions of the cyanoethyl group, the hydrogenation leading to the 3-aminopropyl group seems to be interesting because the latter adds to $\alpha$-amino acid $N$-carboxyanhydride (NCA) and thus initiates the polymerization of NCA. Therefore, $\operatorname{poly}(N$-cyanoethylglycine) is the precursor of a polymeric initiator for the graft copolymerization of $\alpha$-amino acid NCA to produce a branched or a multi-chain $\operatorname{poly}(\alpha$-amino acid).

On account of the sensitivity of $\alpha$-amino acid NCA toward water, alcohols, amines, and acids, the NCA polymerization is usually conducted in aprotic solvents. In contrast to common poly( $\alpha$-amino acid)s which are soluble only in hydroxylic solvents, poly( $N$-alkylamino acid)s

* Present Address: Katata Research Center, Toyobo Co., Ltd., 1300-1, Honkatata, Otsu, Shiga 520-02, Japan. are soluble in aprotic organic solvents. This property of poly $(N$-alkylamino acid $)$ s enables their use as polymeric initiators to synthesize branched poly( $\alpha$-amino acid $)$ s by the graft copolymerization. In poly $(N$-alkylamino acid $) s$, the main-chain amide bonds tend to assume either trans or cis conformation., ${ }^{2,3}$ This property of poly( $N$-alkylamino acid $) s$ allows different conformational states to be possible and renders flexibility. ${ }^{4}$ Furthermore, the participation of cis amide bond makes the polymer structure somewhat more compact. ${ }^{5}$

If the hydrogenated poly( $N$-cyanoethylglycine), that is, $\operatorname{poly}(N-3$-aminopropylglycine), is an initiator for the polymerizations of $\alpha$-amino acid NCA's carrying different functional substituents, the resulting branched poly ( $\alpha$-amino acid) should be differently functionalized along a flexible and compact chain. This situation seems to be very favorable for binding and transporting various kinds of small molecules effectively. Some functional polymers along this line, such as serum albumin ${ }^{6}$ and hydrophobic branched 
polyethyleneimine, ${ }^{7}$ have been noted to bind and transport small molecules effectively.

As the starting polymer to develop branched poly $(\alpha$-amino acid)s which bind and transport small molecules effectively, we synthesized and characterized poly( $N$-cyanoethylglycine $)$.

\section{EXPERIMENTAL}

\section{Reagents}

$\mathrm{N}$-Cyanoethylglycine was synthesized from glycine and acrylonitrile in alkaline solution. ${ }^{8}$ $N$-Carbobenzyloxy $-N$-cyanoethylglycine was treated with thionyl chloride at $60^{\circ} \mathrm{C}$ for $30 \mathrm{~min}$ to obtain $N$-cyanoethylglycine NCA. ${ }^{9}$ The NCA was purified by recrystallization from $\mathrm{AcOEt} / n$ $\mathrm{C}_{6} \mathrm{H}_{14}$; yield $63.4 \%, \mathrm{mp} 108.5^{\circ} \mathrm{C}$ (lit. ${ }^{9} \mathrm{mp} 105^{\circ} \mathrm{C}$ ).

Anal. Calcd for $\mathrm{C}_{6} \mathrm{H}_{6} \mathrm{~N}_{2} \mathrm{O}_{3}$ : C, 46.76; H, 3.92; $\mathrm{N}, 18.18$. Found: C, 47.05; H, 3.76; N, 18.36. A direct synthesis of $N$-cyanoethylglycine NCA from $N$-cyanoethylglycine and trichloromethyl chloroformate ${ }^{10}$ was unsuccessful.

$\mathrm{N}$-Cyanoethylglycine NCA was added into a large excess of $\mathrm{Et}_{2} \mathrm{NH}$, and the mixture was distilled in vacuum to obtain $N$-cyanoethylglycine diethylamide.

$N$ - $n$-Butylglycine NCA and $N$ - $n$-butylglycine diethylamide were synthesized as reported previously. ${ }^{11}$

Poly $(N$-cyanoethylglycine $)$ was synthesized as follows: $N$-cyanoethylglycine NCA $\left(5 \times 10^{-1}\right.$ mol/l) and $N$-cyanoethylglycine diethylamide $\left(2.5 \times 10^{-2} \mathrm{~mol} / l\right)$ were dissolved in $\mathrm{HCONMe}_{2}$. The mixed solution was sealed into a glass ampoule under vacuum and allowed to react at room temperature for 30 days. When the infrared absorptions at 1850 and $1780 \mathrm{~cm}^{-1}$ which are characteristic of NCA disappeared, the reaction solution was poured into ether to precipitate the reaction product. The product $\operatorname{poly}(N$ cyanoethylglycine) was precipitated three times from acetone solution with either.

\section{Procedures}

The rate of nucleophilic addition reaction of amines to $\mathrm{N}$-cyanoethylglycine NCA was determined as following. In a constant volume apparatus kept at $25^{\circ} \mathrm{C}$, the $\mathrm{HCONMe}_{2}$ solutions of $N$-cyanoethylglycine NCA $(0.1 \mathrm{~mol} / l)$ and appropriate amines $(0.1 \mathrm{~mol} / \mathrm{l})$ were mixed. The amount of carbon dioxide liberated in the re- action was measured, ${ }^{12}$ and the conversion of NCA was calculated. From the time-conversion curve thus obtained, the first-order rate constant was determined.

Infrared spectra ( $\mathrm{KBr}$ disk) of poly $(N$-cyanoethylglycine) was investigated using Shimazu IR $27 \mathrm{G}$ spectrometer.

$100-\mathrm{MHz}$ nuclear magnetic resonance spectra ( $\mathrm{Me}_{2} \mathrm{SO}-d_{6}$ solution) of poly ( $N$-cyanoethylglycine) was investigated at $31.5^{\circ} \mathrm{C}$ using Varian $\mathrm{HA}-100$ spectrometer.

The molecular weight of poly $(N$-cyanoethylglycine) was determined from the vapor-pressure depression of the aqueous solution using Hitachi117-type apparatus.

The amino groups in polymers and initiators were determined by the back-titration of $N / 100$ $\mathrm{HCl}$ solution with $N / 100-\mathrm{NaOH}$ solution using Hiranuma RAT-101-type potentiometer.

$\mathrm{X}$-ray analysis of poly( $N$-cyanoethylglycine) was carried out with powderic samples pretreated at $78^{\circ} \mathrm{C}$ or $100^{\circ} \mathrm{C}$.

\section{RESULTS AND DISCUSSION}

\section{Polymerization of $\mathrm{N}$-Cyanoethylglycine $\mathrm{NCA}$}

Using $N$-cyanoethylglycine diethylamide as an initiator $N$-cyanoethylglycine NCA was polymerized in $\mathrm{HCONMe}_{2}$ at room temperature, the NCA/initiator molar ratio being 20 . To complete the polymerization, it took about three months when the NCA concentration was 0.1 $\mathrm{mol} / l$, and about one month when the NCA concentration was $0.5 \mathrm{~mol} / l$. This is much slower than the polymerizations of the usual $\alpha$-amino acid NCA's. ${ }^{13}$ Hanby, et al. ${ }^{14}$ and Ballard and Bamford $^{15}$ have investigated the reactivities of $N$-substituted $\alpha$-amino acid NCA and found that they were usually less reactive than unsubstituted $\alpha$-amino acid NCA's. The low reactivity of $N$-substituted $\alpha$-amino acid NCA has been interpreted in terms of steric hindrance by the $N$-substituent in the propagation reaction. $N$-Cyanoethylglycine diethylamide and $N$ - $n$-butylglycine diethylamide were considered as the models for the growing ends of the polymerizations of $N$-cyanoethylglycine NCA and $N$-n-butylglycine NCA, respectively, and their $\mathrm{p} K_{\mathrm{a}}$ values and the second-order rate constant for the nucleophilic addition reaction 
Poly $(N$-cyanoethylglycine $)$

Table I. $\mathrm{p} K_{\mathrm{a}}$ values of amine

$\mathrm{R}-\mathrm{NH}-\mathrm{CH}_{2}-\mathrm{CO}-\mathrm{NEt}_{2}$ and their nucleophilic addition reaction ${ }^{a}$ to $N$-cyanoethylglycine NCA

\begin{tabular}{ccc}
$\mathrm{R}$ & $\mathrm{p} K_{\mathrm{a}}^{\mathrm{b}}$ & $k, \mathrm{~mol}^{-1} l \mathrm{~min}^{-1}$ \\
\hline$-\mathrm{CH}_{2} \mathrm{CH}_{2} \mathrm{CN}$ & 6.44 & $6.5 \times 10^{-3}$ \\
$-\mathrm{CH}_{2} \mathrm{CH}_{2} \mathrm{CH}_{2} \mathrm{CH}_{3}$ & 8.95 & $6.1 \times 10^{-1}$
\end{tabular}

a Solvent, $\mathrm{HCONMe}$; temp, $25^{\circ} \mathrm{C} ;[\mathrm{NCA}]_{0}=0.1$ $\mathrm{mol} / l ;[\text { amine }]_{0}=0.1 \mathrm{~mol} / l$.

b Determined by titration.

towards $N$-cyanoethylglycine NCA were determined and are compared in Table I. It is conceivable that the low reactivity of $\mathrm{N}$-cyanoethylglycine NCA is due not only to the steric hindrance of $N$-substituent but also to the low basicity of terminal amino group. Despite that the two sorts of amines carry an $N$-substituent of similar size, the nucleophilic reactivity of $\mathrm{N}$-cyanoethylglycine diethylamide is only about $1 / 100$ as small as that of $N$-butylglycine diethylamide. Furthermore, the former is less basic by $c a .2 .5 \mathrm{p} K_{\mathrm{a}}$ unit than the latter. These findings indicate that the terminal amino group in the polymerization of $\mathrm{N}$-cyanoethylglycine NCA is deactivated by the strongly electron-withdrawing cyanoethyl group, resulting in a slow polymerization.

\section{Properties of Poly(N-cyanoethylglycine)}

The reaction solution was homogeneous throughout the polymerization. The resulting polymer was white and powderic. The amine concentration was unchanged before and after the polymerization. Under the condition that the NCA/initiator molar ratio was 20 , the molecular weight of the resulting polymer, which was collected from the polymerization solution at the complete conversion of NCA, was determined to be 1700 by the vapor-pressure depression method. On the other hand, the content of amino group in the polymer was $0.559 \mathrm{meq} / \mathrm{g}$, which corresponded to the molecular weight 1790. Both values are in close agreement with each other. The average degree of polymerization is 15.2 , which is a little smaller than 21 , the expected values from the NCA/initiator molar ratio. ${ }^{16}$ These observations indicate that the polymerization of $\mathrm{N}$-cyanoethylglycine $\mathrm{NCA}$
Table II. Properties ${ }^{a}$ of poly $(N$-cyanoethylglycine $)$

\begin{tabular}{rrrrrrr}
\hline $\mathrm{mp},{ }^{\circ} \mathrm{C}$ & $\mathrm{MW}$ & $\begin{array}{c}\text { Terminal } \\
\text { amine, } \\
\text { meq/g }\end{array}$ & & \multicolumn{3}{c}{ Elemental analysis } \\
\hline $118-124$ & $1700^{\mathrm{b}}$ & $0.55^{\mathrm{c}}$ & 15.2 & 53.40 & 5.79 & 24.87 \\
$(2465)$ & $(0.406)$ & $(21)$ & $(54.40)$ & $(5.76)$ & $(25.59)$ \\
\hline
\end{tabular}

a Theoretical or calculated values are shown in parentheses.

b Determined by vapor-pressure depression.

- Determined by potentiometric titration.

d Calculated on the basis of terminal amine content.

proceeds via normal-amine-type mechanism, ${ }^{17}$ and goes to the completion without termination reactions. The properties of poly $(N$-cyanoethylglycine) are summarized in Table II.

$\mathrm{Poly}(\mathrm{N}$-cyanoethylglycine) is soluble in $\mathrm{HCO}$ $\mathrm{NMe}_{2}, \mathrm{Me}_{2} \mathrm{SO}$, and water, slightly soluble in $\mathrm{Me}_{2} \mathrm{CO}$ (in 30-50 times the amount of solvent), and insoluble in $\mathrm{MeOH}$, dioxane, and ether. The good solubility of polymer in organic solvents, which is undoubtedly related to the $\mathrm{N}$ substitution, is favorable for the further reactions of the polymer. However, the solubility of poly $(N$-cyanoethylglycine $)$ is inferior to poly$(N$ - $n$-butylglycine) $(\mathrm{DP}=30)$ which is also soluble in $\mathrm{MeOH}$ and $\mathrm{CHCl}_{3}$.

Structure of Poly(N-cyanoethylglycine)

The IR spectra of $N$-cyanoethylglycine NCA and its polymer are shown in Figure 1. The 1850- and $1780-\mathrm{cm}^{-1}$ absorptions due to the fivemembered cyclic acid-anhydride group of NCA do not appear in the spectrum of polymer. In the polymer, a strong absorption due to the peptide carbonyl group is observed at $1660 \mathrm{~cm}^{-1}$. The sharp absorption at $2250 \mathrm{~cm}^{-1}$ is characteristic of nitrile group.

The $100-\mathrm{MHz}$ NMR spectrum of $\operatorname{poly}(N-$ cyanoethylglycine) is shown in Figure 2. Two resonance signals at 4.61 and $4.20 \mathrm{ppm}$ are ascribable to the main-chain $\mathrm{C}^{\alpha} \mathrm{H}_{2}$ protons. The upfield signal is assigned to the $\mathrm{C}^{\alpha} \mathrm{H}_{2}$ protons adjacent to trans-peptide bond, according to the NMR investigations on a series of poly $(N$-alkylglycine)s by Sisido, et al. ${ }^{18,19}$ The resonance signal at $3.56 \mathrm{ppm}$ is assignable to the $\mathrm{C}^{\beta} \mathrm{H}_{2}$ protons and that at $2.67 \mathrm{ppm}$ to the $\mathrm{C}^{\gamma} \mathrm{H}_{2}$ protons. For this assignment, the NMR spectra of poly $(N-n$-butylglycine $)$ and poly $(N-n$-propyl- 
glycine) were used. The area ratio of the three kinds of signals are $1: 1: 1$. The ratio of the peak areas of the high and the low $\mathrm{C}^{\alpha} \mathrm{H}_{2}$ signals indicates that the main-chain peptide bonds of poly $(N$-cyanoethylglycine) consists of about $70 \%$ of cis form and about 30\% of trans form. According to Sisido, et al., ${ }^{19}$ the trans/cis ratio of peptide bond in $\mathrm{N}$-acetyl, $\mathrm{N}$-alkyl-L-alanine dimethylamide varies with the $N$-alkyl group: the cis content in $\mathrm{CH}_{2} \mathrm{Cl}_{2}$ at $35^{\circ} \mathrm{C}$ is $18 \%$ for $\mathrm{N}$ -
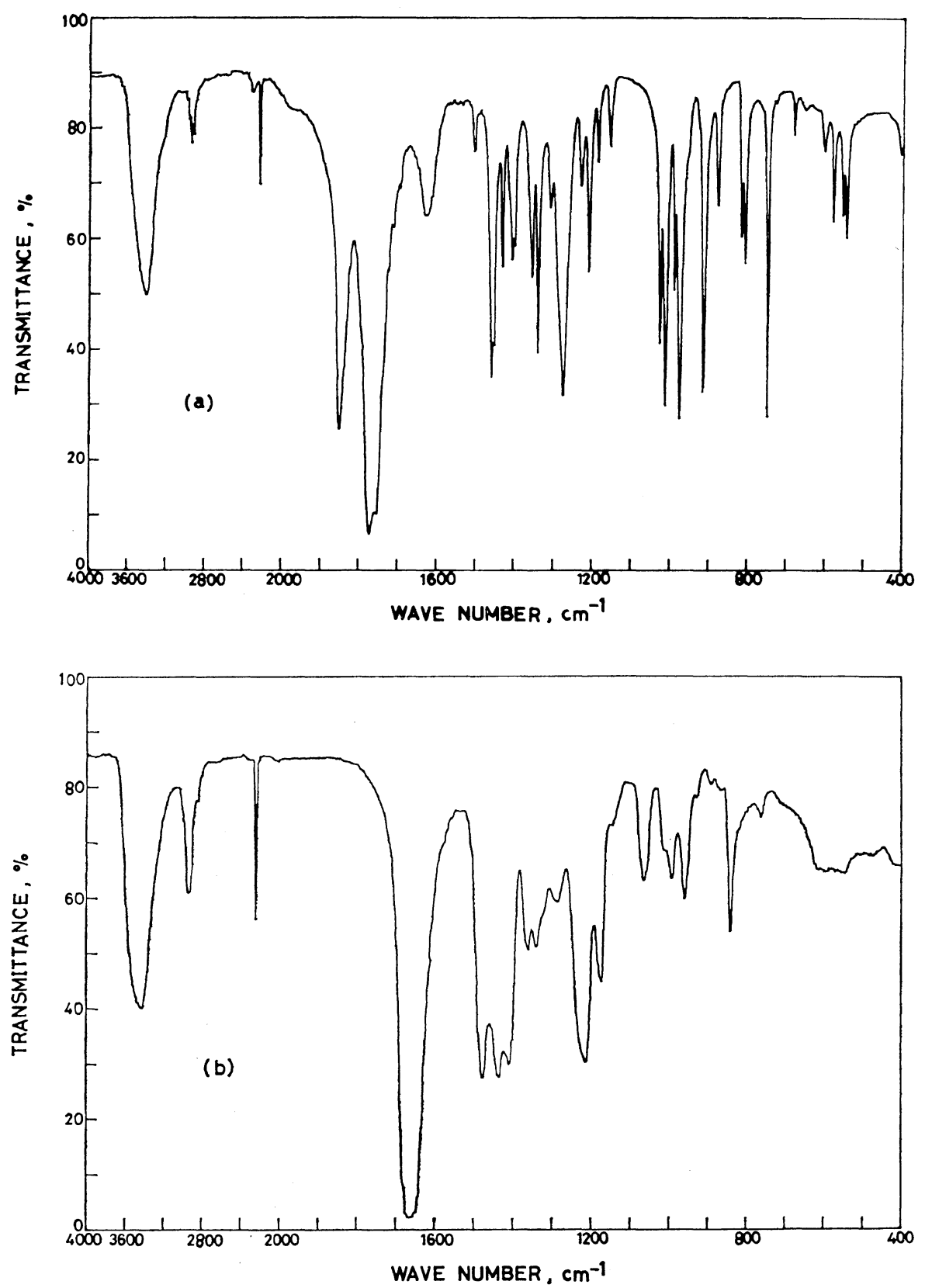

Figure 1. Infrared spectra of $N$-cyanoethylglycine NCA (a) and poly( $N$-cyanoethylglycine) (b); $\mathrm{KBr}$ disk. 


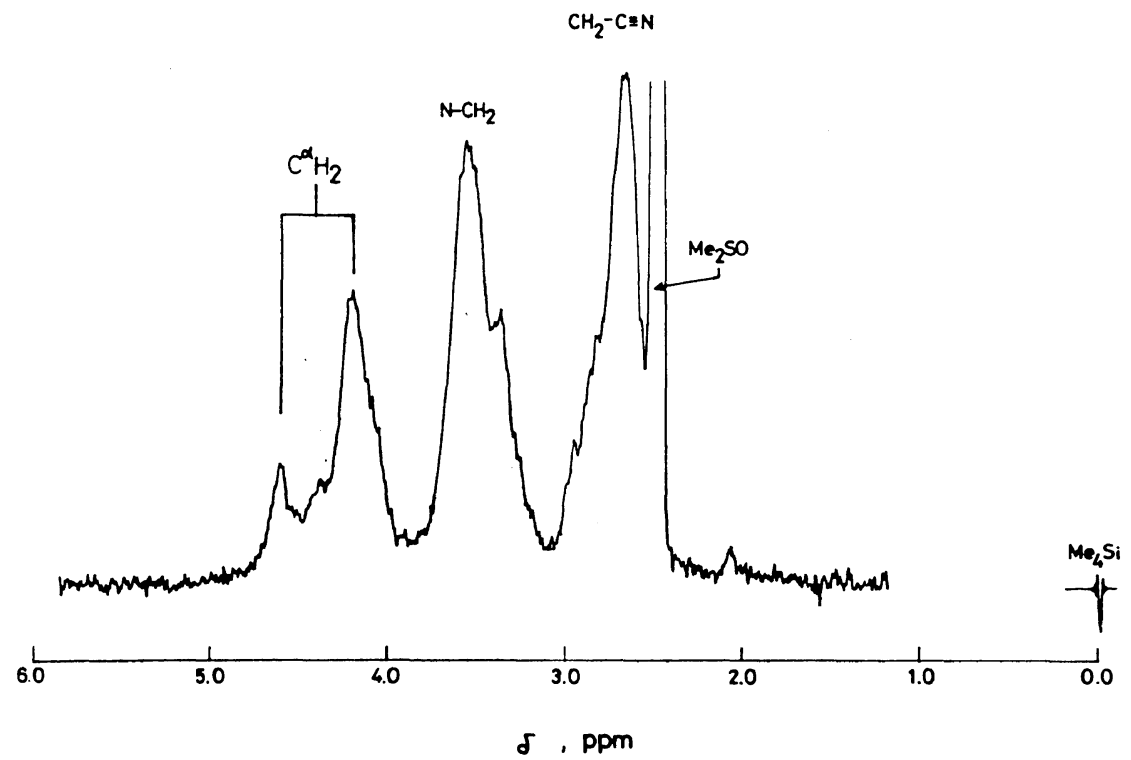

Figure 2. $100-\mathrm{MHz}$ NMR spectrum of poly $\left(N\right.$-cyanoethylglycine) in $\mathrm{Me}_{2} \mathrm{SO}-d_{6}$ at $21.5^{\circ} \mathrm{C}$, $\mathrm{Me}_{4} \mathrm{Si}$ being an internal standard.

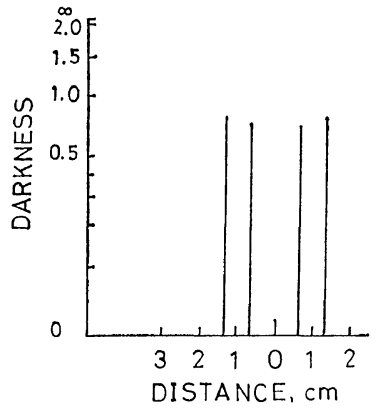

(a)

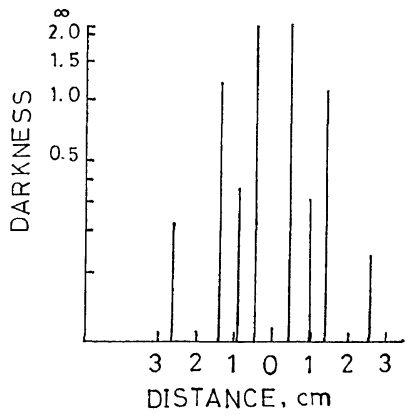

(b) methyl, $56 \%$ for $N$-ethyl, $74 \%$ for $N$ - $n$-propyl, and $71 \%$ for $N$-n-butyl. In general, the cis content increases as the solvent is changed from $\mathrm{CH}_{2} \mathrm{Cl}_{2}$ to $\mathrm{Me}_{2} \mathrm{SO} .^{18}$ These experimental results together suggest that the cis content in $\operatorname{poly}(N$ cyanoethylglycine) would be nearly the same as those in poly $(N-n$-butylglycine $)$ and $\operatorname{poly}(N-n$ propylglycine). Since the cis content of poly $(N$ alkylglycine) is closely related to the bulkiness of the $N$-substituent, ${ }^{18}$ the estimated cis content of poly $(N$-cyanoethylglycine) is reasonable. The occurrence of cis and trans peptide bonds in $\operatorname{poly}(N$-cyanoethylglycine) makes the whole molecule flexible ${ }^{4}$ and allows the polymer to assume a compact conformation. ${ }^{5}$ These conformational features of $\operatorname{poly}(N$-cyanoethylglycine $)$ are promising for the design of a functional polymer to bind and transport small molecules effectively.

The X-ray diffraction pattern of poly $(N$-cyanoethylglycine) was obtained and compared with

Figure 3. Schematic representation of X-ray diffraction patterns: (a), poly $(N$-cyanoethylglycine), DP 15, spacing, 4.9 and $2.7 \AA$; (b), $\operatorname{poly}(N$ - $n$-butylglycine), DP 30, spacing, 13.8, 6.7, 4.6, and $2.7 \AA$. Ordinate is a relative transmittance of light from each diffraction. Abscissa is the distance of each diffraction from the center. The camera distance was $39.96 \mathrm{~mm}$. 
that of $\operatorname{poly}(N$ - $n$-butylglycine) in Figure 3 . It is understandable that poly $(N$-cyanoethylglycine $)$ is less crystalline than poly( $N$ - $n$-butylglycine $)$ because of highly polar pendant nitrile groups.

\section{Reduction of Poly( $N$-cyanoethylglycine)}

The preliminary experiments were carried out to investigate the catalytic hydrogenation of pendant cyanoethyl groups into 3-aminopropyl groups which will be the initiator for the graft polymerization of various $\alpha$-amino acid NCA's. Poly $(\mathrm{N}$-cyanoethylglycine) was dissolved in $\mathrm{H}$ $\mathrm{CONMe}_{2}$ and hydrogenated with Raney $\mathrm{Ni}$ as a catalyst. The conversion of nitrile groups into primary amino groups were found by titration to be $12.7 \mathrm{~mol} \%$. This is equivalent to about 1.2 amino groups per chain, and is far less than that expected. During the hydrogeneration with $\mathrm{H}_{2} / \mathrm{Ni}$, side reactions took place to produce a crosslinked polypeptide. The gel of crosslinked polypeptide must have covered the catalyst surface and thus deactivated it. To overcome this difficulty, an alternative way leading to $\operatorname{poly}(N$ 3-aminopropylglycine) is currently being developed. It involves the preparation of $\mathrm{N}$-(3carbobenzyloxyaminopropyl)glycine by the reaction of bromoacetic acid and $N$-carbobenzyloxy1,3-propanediamine, the polymerization of the amino acid by NCA method, and the decarbobenzyloxylation of the resulting polymer.

To summarize the experimental results, $\mathrm{N}$ cyanoethylglycine was synthesized, and then converted into poly $(N$-cyanoethylglycine $)$ by the NCA method for the first time. The polymer having $\bar{P}_{n} c a .15$ was obtained and it was amorphous and soluble in various aprotic organic solvents. The main-chain peptide bonds of the polymer were composed of cis as well as trans bonds, the former being predominant (ca. 70\%) in $\mathrm{Me}_{2} \mathrm{SO}$.

\section{REFERENCES}

1. S. Tanimoto, Yuki Gosei Kagaku Kyokai-shi (J. Syn. Org. Chem., Japan), 26, 849 (1968).

2. I. Z. Steinberg, W. F. Harrington, A. Berger, M. Sela, and E. Katchalski, J. Am. Chem. Soc., 82, 5263 (1960).

3. F. A. Bovey, J. J. Ryan, and F. P. Hood, Macromolecules, 1, 305 (1968).

4. T. Sugihara, Y. Imanishi, and T. Higashimura, Biopolymers, 15, 1529 (1976).

5. M. Sisido, Y. Imanishi, and T. Higashimura, Macromolecules, 9, 389 (1976).

6. F. Karush, J. Am. Chem. Soc., 72, 2705 (1950).

7. I. M. Klotz and A. R. Sloniewsky, Biochem. Biophys. Res. Comm., 31, 421 (1968).

8. L. L. Mckinney, E. H. Uhing, E. A. Setzkorn, and J.C. Cowan, J. Am. Chem. Soc., 72, 2599 (1950).

9. S. Akabori, S. Morimoto, and E. Iwamoto, Sen-i Kagaku Kenkyu-sho Nenpo, 13, 137 (1958).

10. M. Oya, R. Katakai, and H. Nakai, Chem. Lett., 1143 (1973).

11. Y. Imanishi, K. Sueda, and T. Higashimura, Kobunshi Kagaku (Chem. High Polymers), 30, 61 (1973).

12. M. Sisido, Y. Imanishi, and S. Okamura, Biopolymers, 7, 937 (1969).

13. M. Szwarc, Adv. Polym. Sci., 4, 1 (1965).

14. W. E. Hanby, S. G. Waley, and J. Watson, $J$. Chem. Soc., 3009 (1950).

15. D. G. H. Ballard and C. H. Bamford, J. Chem. Soc., 355 (1958).

16. C. H. Bamford, A. Elliott, and W. E. Hanby, "Synthetic Polypeptides," Academic Press, New York, N.Y., 1956, p 63.

17. Y. Imanishi, Kobunshi (High Polymers), 21, 32 (1972).

18. M. Sisido, Y. Imanishi, and T. Higashimura, Biopolymers, 11, 399 (1972).

19. M. Sisido, Y. Imanishi, and T. Higashimura, Biopolymers, 12, 2375 (1973). 